\title{
RECONSTRUCCION CARDIACA EN GEMELOS TORACOPAGOS MEDIANTE IMAGENES DE TOMOGRAFIA COMPUTADA Y RESONANCIA MAGNETICA
} \author{
Noemí Arrizaga $\mathbf{G}^{(5)}$. \\ 1. Programa de Morfología-ICBM. Facultad de Medicina. Universidad de Chile. \\ 2. Programa Genética Humana-ICBM. Facultad de Medicina. Universidad de Chile. \\ 3. Servicio de Radioterapia. Instituto Nacional del Cáncer. \\ 4. Servicio de Imagenología. Hospital Clínico J. J. Aguirre. Universidad de Chile. \\ 5. Servicio de Neonatología. Hospital Barros Luco. Servicio Salud Metropolitano Sur.
}

Drs. Sandra Arriagada $R^{(1)}$, Rodrigo Moreno $S^{(2,5)}$, Dalivor Herrera $\mathbf{G}^{(3)}$, Cristian Parra $B^{(3)}$, Dulia Ortega $T^{(4)}$,

\begin{abstract}
Congenital malformations are the second childhood mortality cause in in Chile. The purpose of this study is to illustrate the use of advanced imaging techniques for diagnostic of congenital cardiac malformations on conjoined twins. Fetus malformated were preserved in a 10\% formaldeide solution in Teratology Unit of Anatomy Department, Faculty of Medicine at University of Chile. This study begins with conventional techniques, such as $X$-rays and ultrasound of the thoraco- omphalopagus conjoined twins. The images obtained by CT and MR imaging were archived and worked by a computing program (Somavision) that allows an image to be selectively examined and dissected as well as the complete anatomically reconstruction in situ of systems and organs.

The MR imaging was performed at Clinical Hospital JJ Aguirre of University of Chile, and the CT was done at Instituto Nacional del Cáncer, Santiago, Chile whom provided digitalized equipment and software for tridimentional cardiac reconstruction.
\end{abstract}

Key words: Cardiac reconstruction, Computarized tomography, Conjoined thoracopagus, Magnetic resonance.

Resumen: En Chile las malformaciones congénitas son la segunda causa de mortalidad infantil. La colección de fetos y recién nacidos malformados con

Arriagada S, y cols. Reconstrucción cardíaca en gemelos toracopagos mediante imágenes de tomografía computada y resonancia magnética. Rev Chil Radiol 2004; 10 : 139-146.

Correspondencia: Dra. Sandra Arriagada Ríos. Universidad de Chile, Facultad de Medicina, Programa de Morfología-ICBM, Departamento de Anatomía. Correo: Casilla 70079 Santiago 7, CHILE. Fono: 6786086. Fax: 6786785 E-mail: sarriagada@.med.uchile.cl que cuenta la Sección de Teratología del Departamento de Anatomía, Facultad de Medicina de la Universidad de Chile, permite conocer y estudiar patologías que, por su baja frecuencia sólo son conocidas por los especialistas. Los gemelos unidos son una condición, en la cual existe predominio en el sexo femenino y su etiología es desconocida. Se estudia el caso, de gemelos unidos del tipo tóracoonfalópagos, con una fusión amplia desde el esternón hasta la región umbilical, que hubiese requerido de exactitud diagnóstica, para delimitar la interdependencia anatómica y sus posibles consecuencias funcionales, ante una eventual corrección quirúrgica y posible viabilidad. Con este objetivo, se utilizaron técnicas convencionales y avanzadas de imagenología en su estudio, como radiografías, ultrasonografías, TC y RM. Estas dos últimas, se digitalizaron para realizar una reconstrucción anatómica tridimensional in situ con el programa Somavisión.

Palabras claves: Gemelos toracopagos, Reconstrucción cardiaca, Resonancia magnética, Tomografía computarizada.

\section{Introducción}

Las malformaciones congénitas en Chile, son la segunda causa de mortalidad infantil(1). Un tipo particular de malformación son los gemelos unidos 0 siameses, que se presentan entre los embarazos múltiples $^{(2)}$, los cuales han aumentado su frecuencia con el uso de la fertilización asistida ${ }^{(3)}$.

Entre los embarazos múltiples los gemelos monocigóticos, son producto de un óvulo único fecundado en que suele aceptarse que la subdivisión corresponde a la masa celular interna de un blastocito. Los gemelos unidos corresponden a un tipo especial de gemelos monocigóticos o idénticos, en donde se discute si la unión corresponde a una separación 
incompleta o si porciones separadas se vuelven a fusionar, entre el tercer a octavo día postfecundación ${ }^{(4)}$. Las células del blastocisto son totipotenciales para la organogénesis por un corto tiempo, determinando esto el futuro desenlace.

El diagnóstico es evidente con el examen físico externo, sin embargo este no permite constatar claramente la envergadura de las uniones cardíacas y viscerales. El $60 \%$ de los gemelos unidos nacen vivos, un $35 \%$ vive solo un día y no suelen sobrevivir a la separación quirúrgica, cuando presentan fusión cardiaca. Es por tanto un desafío especial la clara identificación y visualización de la malformación cardiaca y visceral, que establecerá el pronóstico y tratamiento definitivo ${ }^{(5,6)}$.

Nuestro objetivo fue realizar un estudio experimental multidisciplinario, para adquirir experiencia en el estudio de gemelas tóracoonfalópagos.

\section{Material y método}

Se utilizó gemelas unidas por el tórax y abdomen de la colección de malformados del Departamento de Anatomía de la Facultad de Medicina, Universidad de Chile, que están previamente fijados y conservados en formalina al $10 \%$.

El estudio se inició con un examen externo, a través de una ficha de autopsia perinatal, que permitió descartar signos dismórficos y malformaciones externas (Figura 1). La presentación de las gemelas corresponde a una unión cara a cara, identificándose como G1 y G2, de sexo femenino, edad gestacional de término y $\mathrm{G} 1$ de mayor tamaño.

El examen radiológico convencional mostró una estructura ósea completa sin signos de deformación, apreciándose débilmente la imagen de órganos compartidos, interpretación que no cambia significativamente, con la ecocardiográfica, que mostró la emergencia de arcos aórticos y pulmonares en ambas gemelas; pero que no permitió precisar los límites de las cavidades y sus respectivos tabiques auriculares y ventriculares (Figuras 2,3).

Para el estudio de la anatomía interna, se recurrió a otras técnicas imagenológicas, que incluyeron tomografía computarizada (TC) y resonancia magnética (RM), para el estudio de órganos internos in situ, que en esta investigación se dirige especialmente a los corazones de ambas gemelas. Se incorporan exámenes de alta resolución y posterior reconstrucción tridimensional, la TC fue realizada en el Instituto Nacional del Cáncer y la RM en el Hospital Clínico de la Universidad de Chile. Se tuvo especial cuidado en posicionar el material en estudio de modo de obtener un máximo de visión y puntos de referencia comparables entre ambos exámenes (Figura 4).
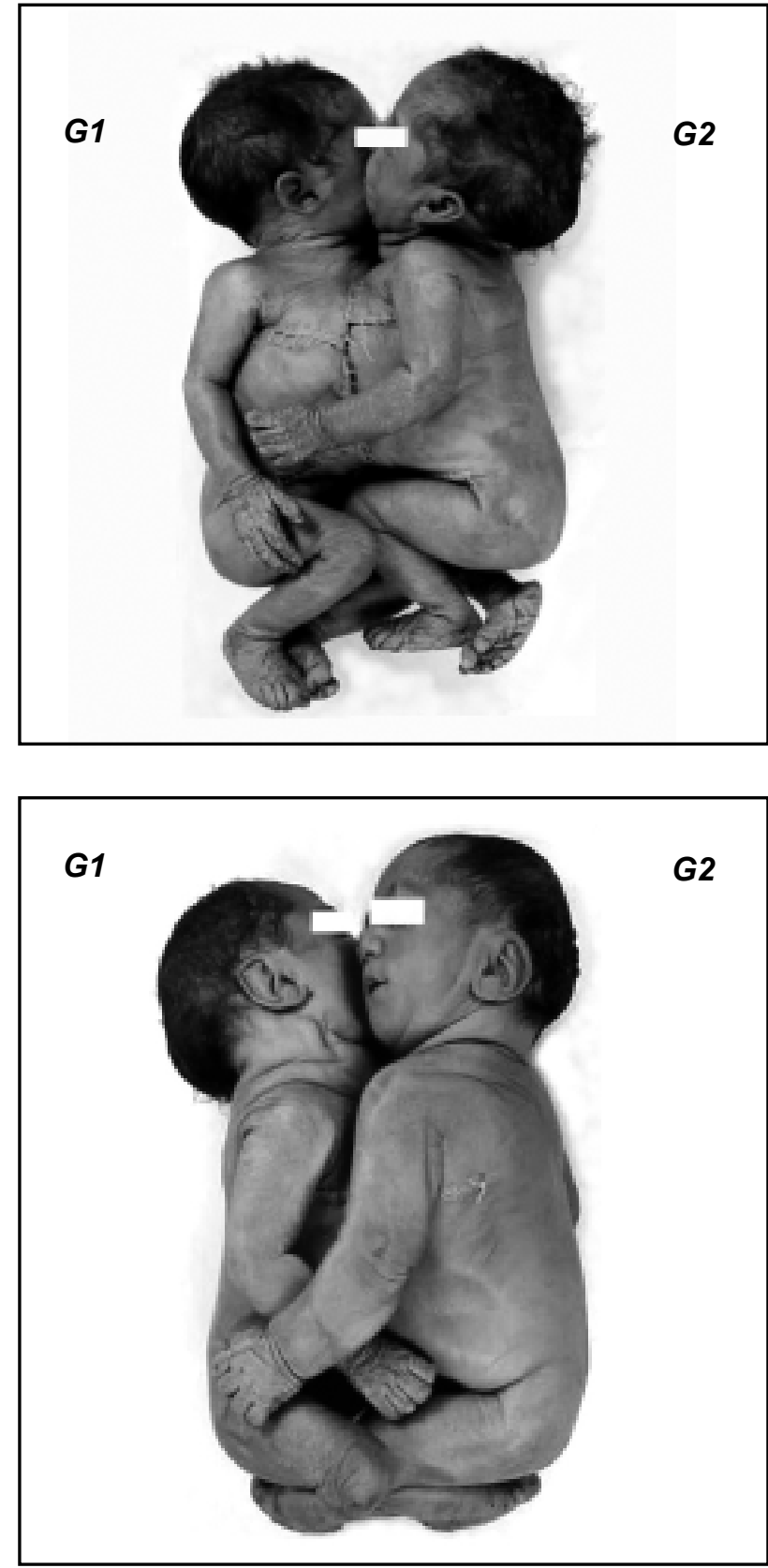

Figura 1 a,b. Imágenes de gemelas tóraco-onfalópagos conservadas en formalina al $10 \%$, presentación en vista frontal (a) y dorsal (b). Se aprecia una unión amplia, desde la región torácica hasta la umbilical.

G1: Gemela 1; G2: Gemela 2. Esta identificación será usada en todas las figuras.

Se realiza en TC un total de 90 cortes axiales cada $5 \mathrm{~mm}$, desde el cráneo hasta las extremidades inferiores sometiendo a prueba el grado de contraste y precisión de la imagen requerida (Figura 5). En $\mathrm{RM}$, solo se efectuaron 24 cortes de $2,5 \mathrm{~mm}$ de espesor, transversales y sagitales limitados a la región torácica (Figura 6 ).

Las imágenes obtenidas por RM se anexaron a través de un digitalizador VIDAR O VX R-16, para 

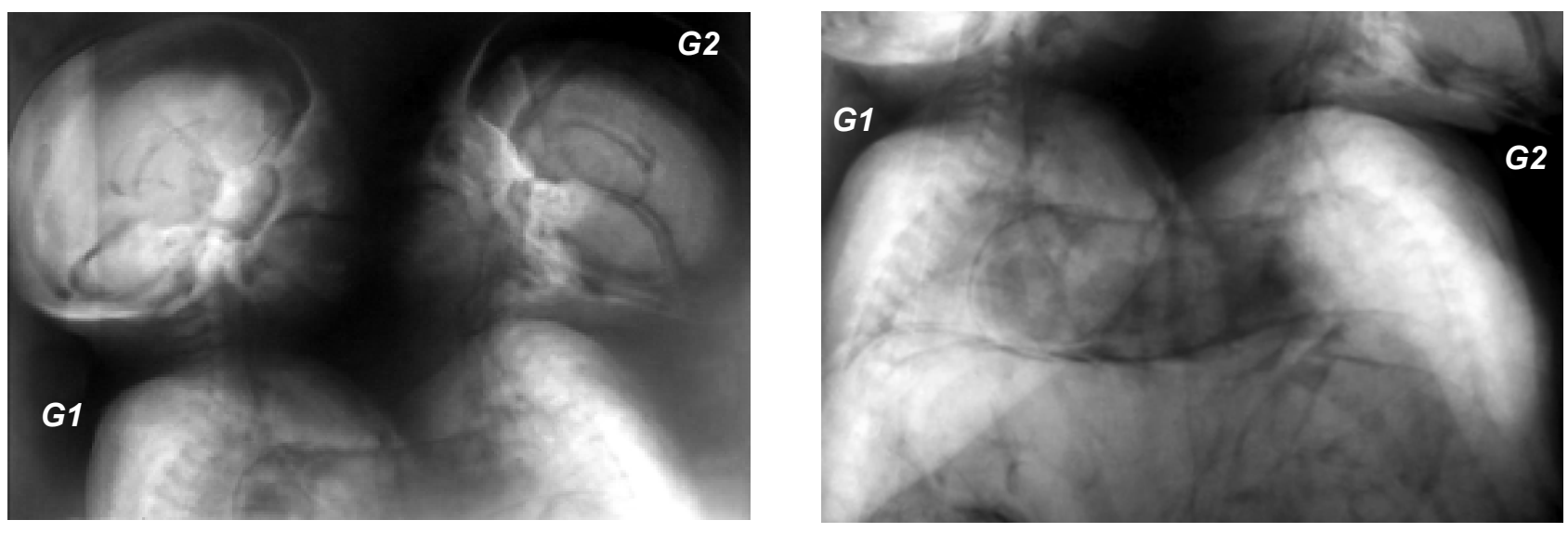

Figura 2 a,b. Radiografías que muestran una estructura ósea completa sin signos de deformación, apreciándose tenuemente la imagen de órganos compartidos.
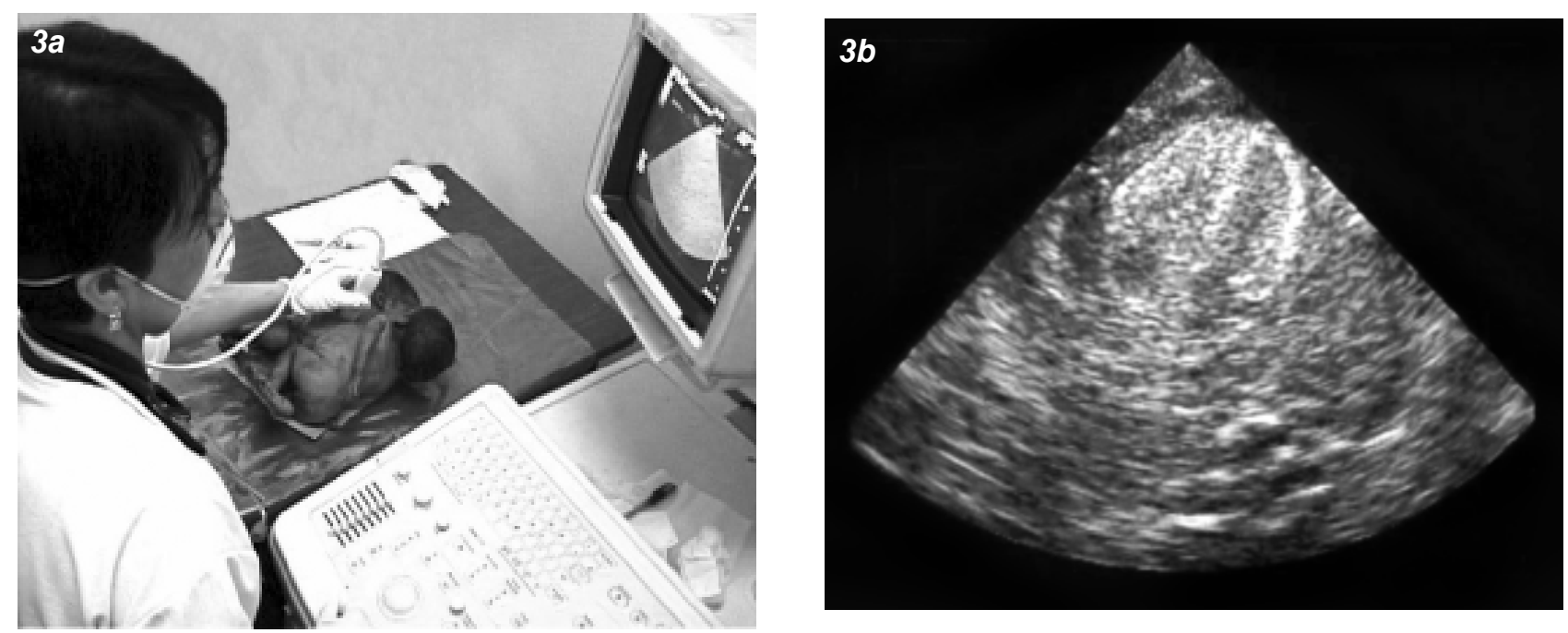

Figura 3 a,b. Ecocardiografía en que se pueden apreciar las paredes cardíacas laterales, sin embargo, existe dificultad para precisar los límites de los tabiques auriculares y ventriculares.

la reconstrucción anatómica tridimensional de las imágenes coplanares del TC y RM con el programa Somavisión. Este último permite delinear y pintar partes blandas y huesos contorneando plano a plano y corte a corte, otorgándole una unidad de densidad a cada tejido logrando una reconstrucción anatómica tridimensional en los planos frontal y sagital, modelando órganos y estructuras parcial, completa y simultánea de ambas gemelas.

\section{Resultados}

Se evidencia que, tanto las estructuras del cráneo como del esqueleto se denotan claramente con todas las técnicas de imágenes, sin embargo, el estudio de la región del tórax requirió la incorporación de imágenes de mayor contraste y definición como TC y RM. La ausencia de esternón y la unión desde el tórax hasta la región umbilical, confirman que corresponden a gemelos unidos por tórax y abdomen o tóracopago-onfalópagos, comparten cavidad pericárdica y abdominal en la cual sólo el hígado está unido (Figura 5). Se logra identificar ambas clavículas y manubrios esternales.

Se concluyó en la evaluación cardiológica, que G1 presentaba un corazón en dextroposición una aurícula o atrio único con la pared poco pectinada, ventrículo izquierdo hipoplásico y G2 con una aurícula o atrio regular y la pared septal del ventrículo con dos comunicaciones interventriculares (CIV), una alta tipo canal y otra baja perimembranosa (Figuras $6,7)$.

Se logra una reconstrucción tridimensional anatómica de ambos corazones, que permitió advertir la presencia de dos corazones independientes con cavidades auriculares y ventriculares, a través de la reconstrucción de las superficies de los órganos explorados in situ (Figuras 8, 9). 

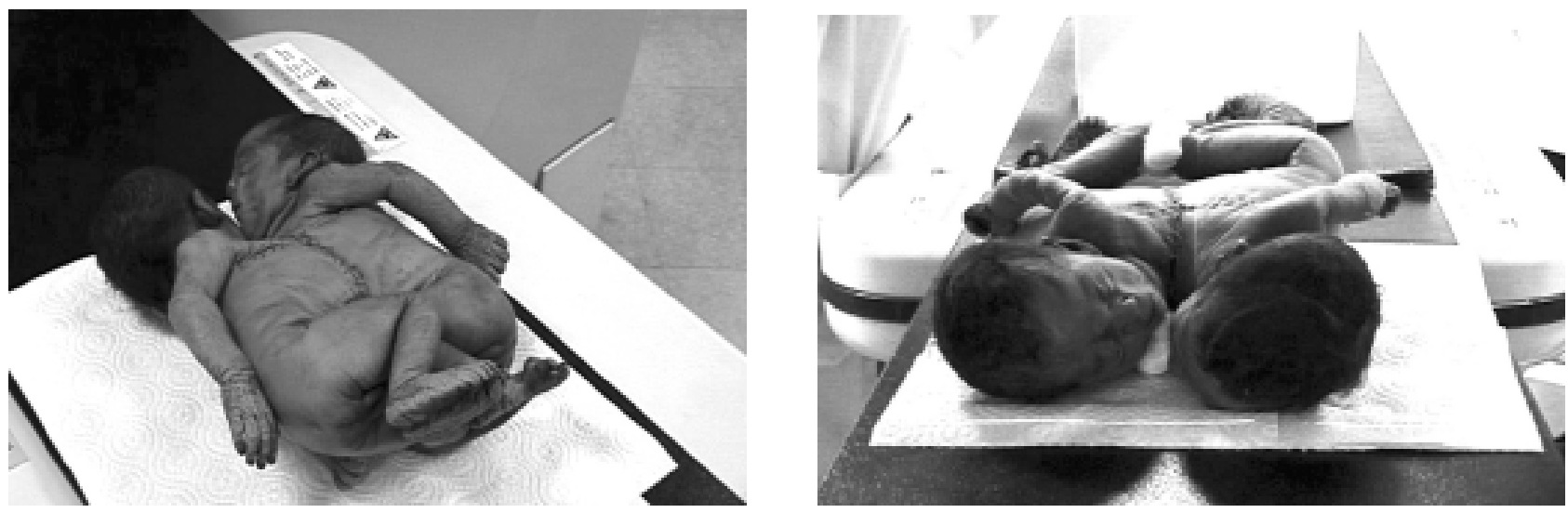

Figura 4 a,b. Posicionamiento del las gemelas en TC (a) y RM (b). Para obtener la imagen requerida se posicionaron los cuerpos, cuidando de exponer el tórax y evitar la sobreproyección de las extremidades.
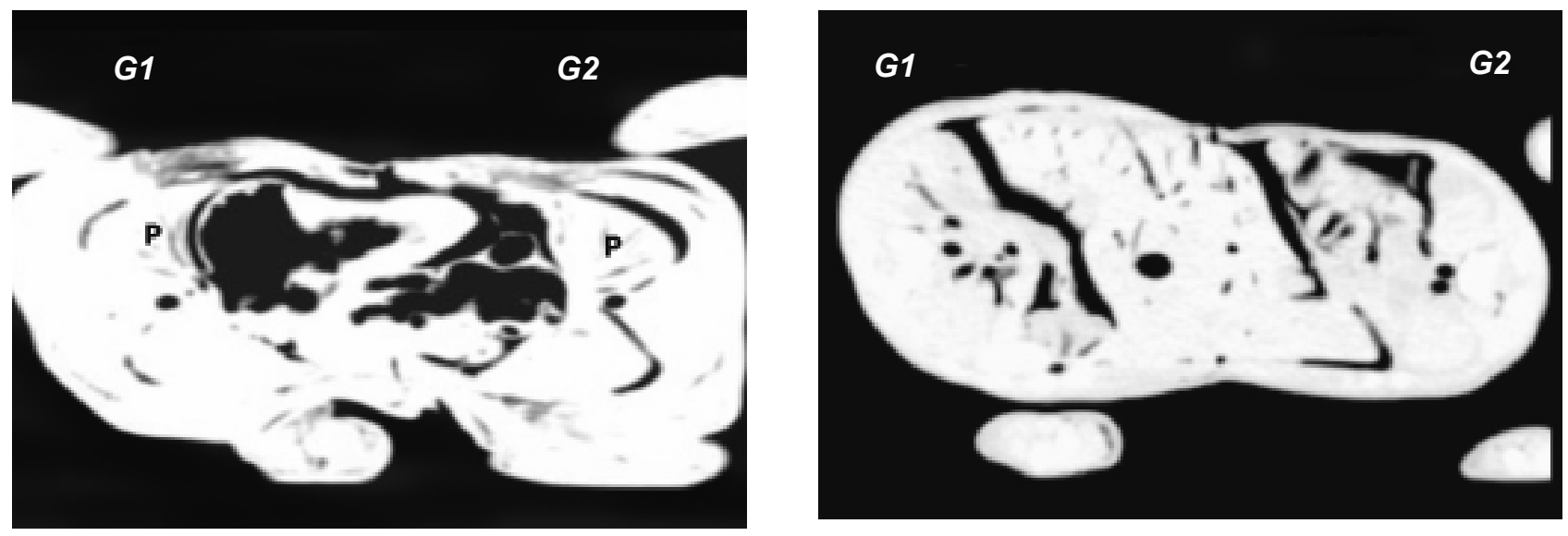

Figura 5 a,b. TC cortes axiales. a: Se diferencia el parénquima pulmonar de ambos gemelos $(P)$ y entre ellos dos corazones; no siendo posible determinar si son independientes. b: Corte a nivel del hígado demostrando el parénquima claramente compartido.
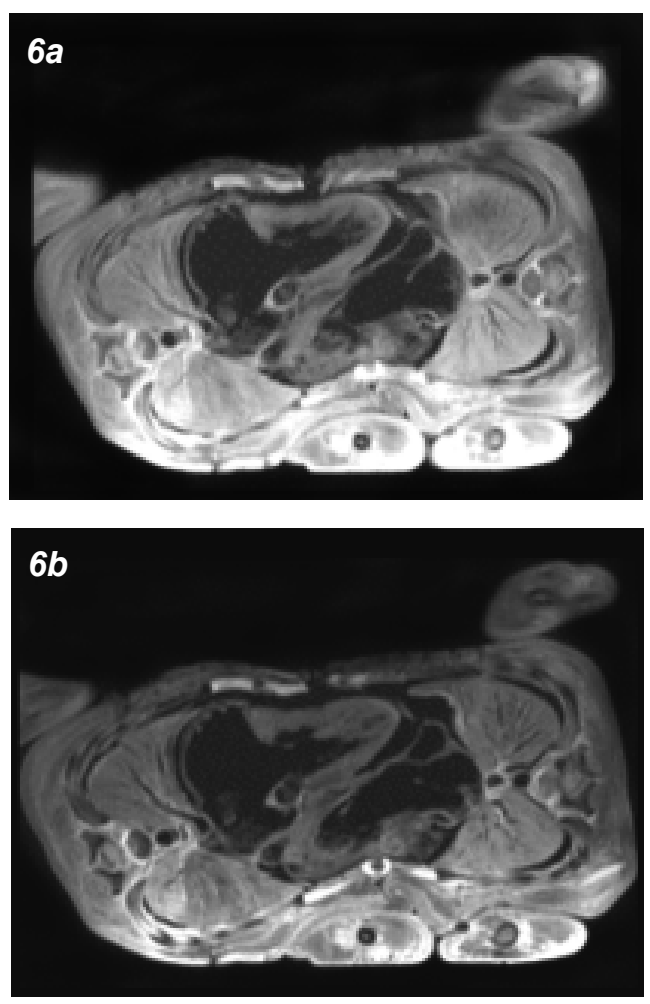

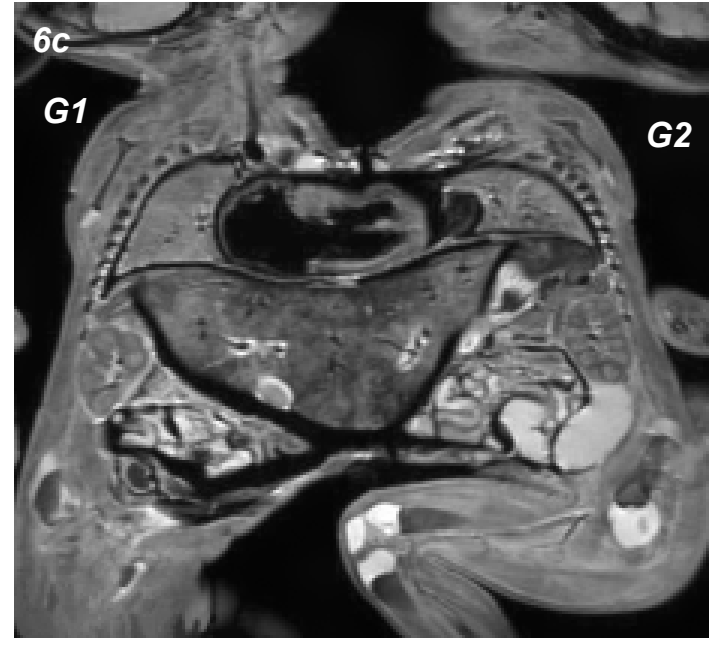

Figura 6 a-c. Imágenes de RM, que muestran a G1 con un corazón en dextro posición, un atrio o aurícula única amplia y un ventrículo izquierdo hipoplásico. G2 tiene un atrio regular y dos CIV, una alta tipo canal y otra baja peri membranosa. 


\section{A V I S O}




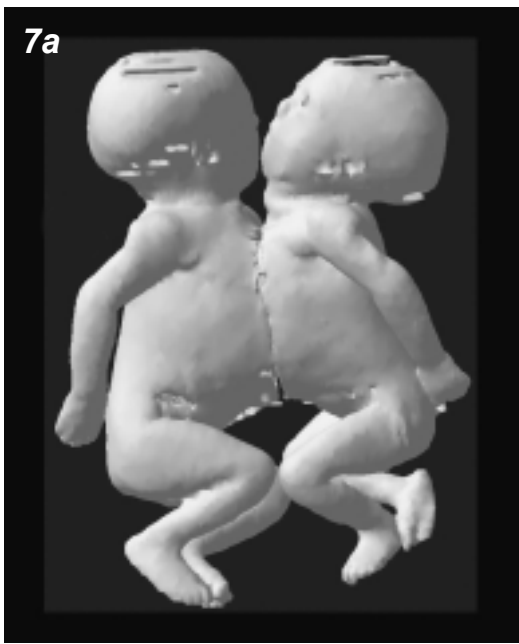

$7 b$

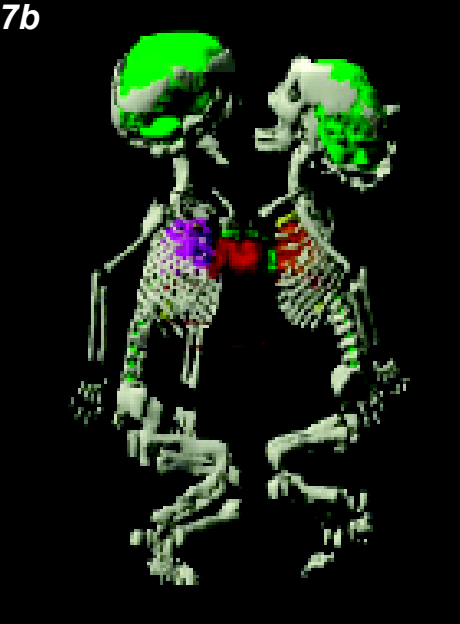

$7 c$

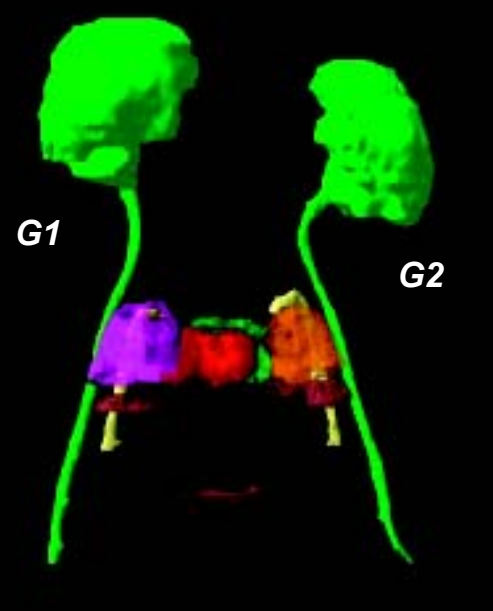

Figura 7 a-d. Reconstrucción anatómica tridimensional que muestra el producto de la zonificación y dibujo de partes blandas, obtenida a través del programa Somavision. a: Vista externa. b: Esqueletos. c: Sistema nervioso central y cámaras cardiacas. d: visión axial de pulmones y cámaras cardiacas.
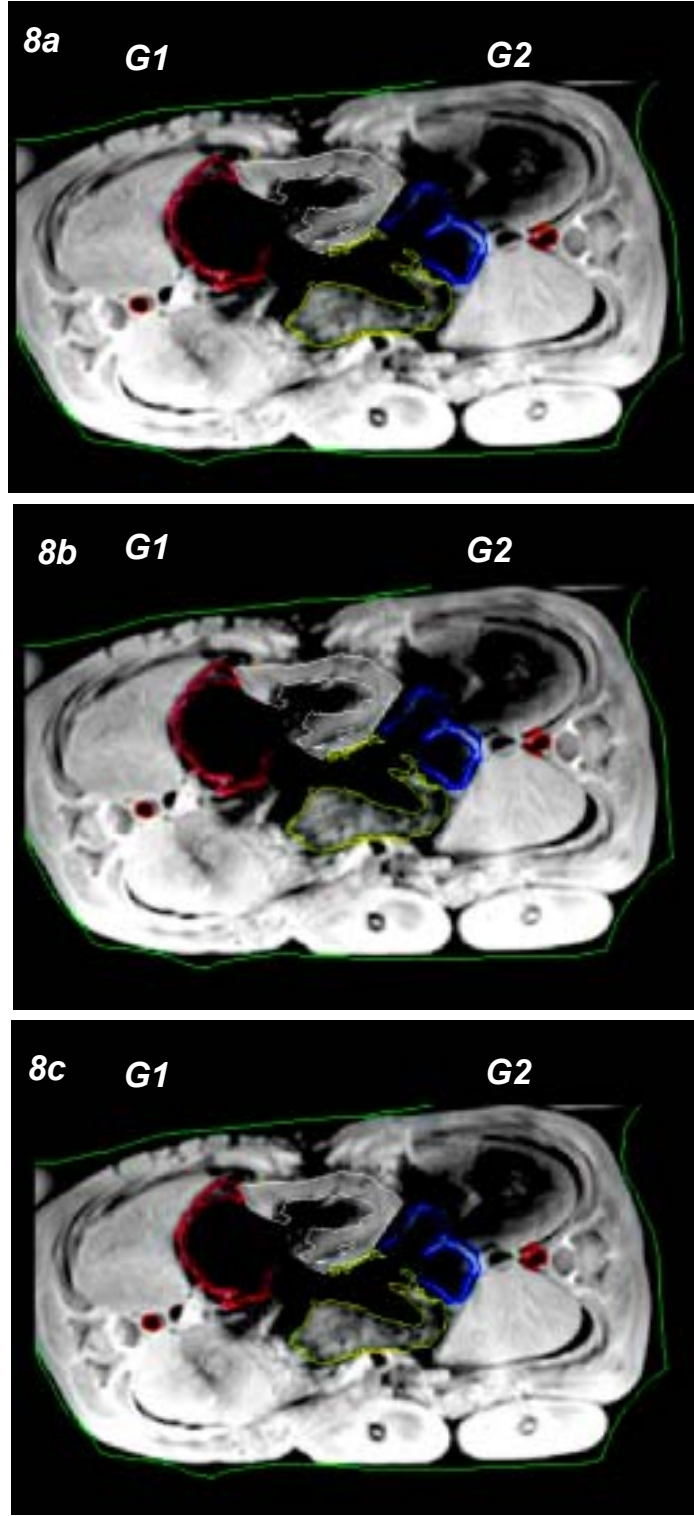

Figura 8 a-d.

Zonificación corte a corte, que permite la reconstrucción

tridimensional de las cavidades

cardíacas,

identificando cada cámara con un color específico. Para G1 en Rojo el atrio ampliado y Plomo el ventrículo

hipoplásico, y para G2 en Azul el atrio y en Verde el

ventrículo.

Figura 9. Reconstrucción cardíaca tridimensional, la cual puede ser rotada en $360^{\circ}$ en el computador. Muestra cavidades cardíacas completas e independientes. En G1 (a) en Rojo el atrio amplio y (b) Plomo el ventrículo hipoplásico se ve alargado, y en G2 (c) en Azul un atrio y (d) en Verde un ventrículo, ambos de características normales.
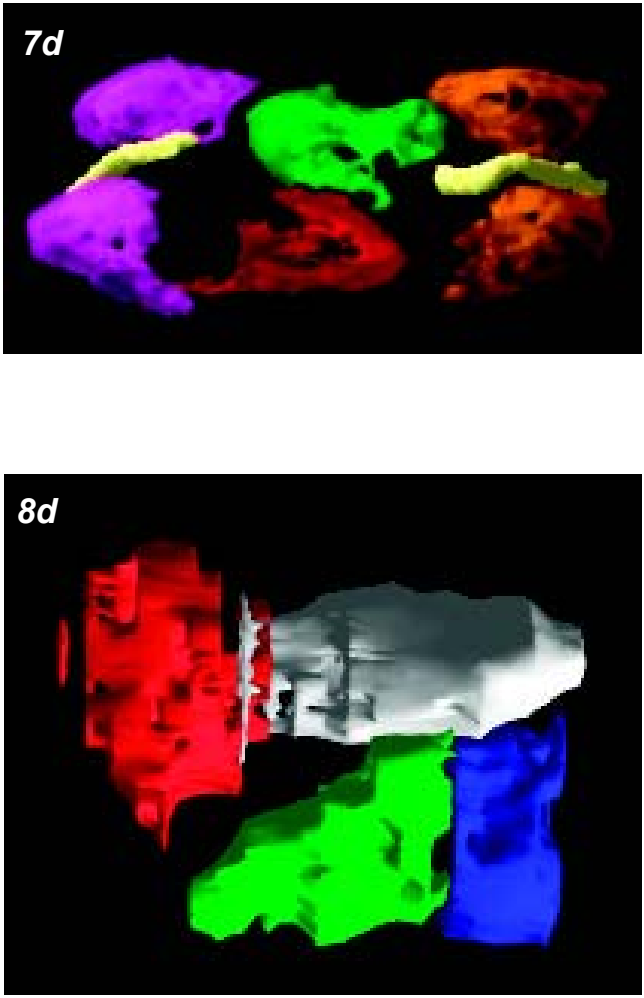


\section{Discusión}

Los gemelos unidos es una anomalía poco frecuente, constituyendo el $0,1 \%$ del total de malformaciones de acuerdo a los registros del Estudio Colaborativo Latinoamericano de Malformaciones Congénitas o $\operatorname{ECLAMC}^{(7)}$. Dos tercios corresponden al tipo toracópagosonfalópagos, que presentan una unión desde la región del tórax hasta la umbilical, quedando independiente la región baja del abdomen y la pelvis, cada gemelo presenta sus cuatro extremidades y cabeza completamente desarrolladas ${ }^{(8)}$.

La etiología de los gemelos unidos es desconocida, pero existe un predominio del sexo femenino en proporción 7 a 3 , lo que algunos investigadores atribuyen a una anormal inactivación del cromosoma $X^{(9)}$. Se ha descrito un incremento significativo en la frecuencia de separación de cigotos produciendo gemelos, después de la inducción artificial de la ovulación ${ }^{(3)}$, lo que hace plantear una interacción genético ambiental en la alteración del desarrollo embrionario. Se sabe que las anomalías de lateralización del embrión en la formación del eje izquierda/derecha son más frecuentes en los gemelos unidos humanos, que en los hijos nacidos de parto no múltiple o en los gemelos dicigotos ${ }^{(10)}$. En seres humanos con alteraciones de lateralización, se ha identificado mutaciones de la proteína en dedos de zinc del cerebelo (ZIC3), de la familia de factores de trascripción Gli localizados en el cromosoma $X^{(11)}$. Herencia autosómica recesiva ${ }^{(9)}$ y dominante ${ }^{(12)}$, ha sido propuesta también, para la ocurrencia de gemelos monocigotos.

Las cardiopatías congénitas están presentes en el $75 \%$ de gemelos toracópagos con algún grado de fusión del saco pericárdico en un $90 \%$ de los $\operatorname{casos}^{(13)}$. Un alto porcentaje son malos candidatos para cirugía debido al grado de fusión y la complejidad de las anomalías cardiacas por lo cual una correcta evaluación es necesaria.

Aun cuando pudimos en nuestra investigación identificar claramente las alteraciones anatómicas, existen factores que representan una desventaja, como lo es la fijación en formalina, que impide diferenciar tejidos que in vivo tienen distinta densidad. Además, en el material fijado existen algunas relaciones anatómicas y funcionales, que se pierden, como ocurre con el colapso de las válvulas y ausencia de flujo sanguíneo, también para estructuras anatómicas pequeñas, el espesor de los cortes de 2,5 milímetros impidió visualizarlas bien.
Identificamos sin embargo, factores favorables al hecho de trabajar con material fijado, como lo es la ausencia de movimiento, lo que permite mantener la posición en los distintos exámenes realizados, lográndose una reconstrucción anatómica tridimensional in situ, de órganos blandos en distintos planos, con buenas imágenes que permiten apreciar claramente las malformaciones. En este caso en particular, logramos una visión equivalente a una autopsia(14), diagnosticando adecuadamente las cardiopatías y uniones viscerales. Las imágenes tridimensionales obtenidas son más cercanas a la estructura anatómica real, que una imagen bidimensional, las cuales, al estar digitalizadas nos permiten compartir nuestra experiencia y poder compararla a futuro con posibles casos $^{(15)}$.

Eventualmente estas imágenes pueden servir, para modelar posibles tratamientos. La extensión de nuestra experiencia a fetos o recién nacidos, podría ser realizada con técnicas de $\mathrm{RM}$ en secuencias rápidas, que permiten resolver el problema del movimiento ${ }^{(15,16)}$.

\section{Bibliografía}

1. Instituto Nacional de Estadísticas INE. Compendio estadístico 2003. Imprenta INE, 2004.

2. Quiroz, VH, Sepulveda Wh, Mercado M et al. Prenatal ultrasonographic diagnosis of thoracopagus conjoined twins. J Perinat Med 1989; 17: 297-303.

3. Derom C, Vlietinck R, Deron R, et al. Increased monozygotic twinning rate after ovulation induction. Lancet 1987; 1 (8544): 1236-1238.

4. Zimmermann AA. Embryologic and anatomic considerations of conjoined twins. In: Bergsma, D. ed: Conjoined twins. Birth Defects Orig. Art. Ser. III 1967; 18(1).

5. Nichols BL., et al. General clinical management of thoracopagus twins. In: Bergsma, D., ed: Conjoined twins. Birth Defects Orig. Art. Ser. III 1967; 28(1).

6. Casta A. Cardiovascular evaluation in thoracopagus twins. Circulation 1999; 100: 103.

7. Castilla EE, López-Camelo JS, Oriol JM et al. The epidemiologist of conjoined twins in Latin America. Acta Genet Med Gemellol (Roma) 1988; 37: 111-118.

8. Spencer R. Anatomic description of conjoined twins: a plea for standardized terminology. J. Pediatr Surg 1996; 31: 941-944.

9. Harvey MA, Huntley RM, Smith DW. Familial monozygotic twinning. J Pediatr 1977; 90: 246248. 
10. Cunniff $C$, Jones $\mathrm{KL}$, Jones MC. Laterality defects in conjoined twins. Am J Med Genet 1988; 31 : 669-677.

11. Burdine RD, Schier AF. Conserved and divergent mechanisms in left-right axis formation. Genes Dev 2000; 14: 763-776.

12. Shapiro LR, Zemek L, Shulman MJ. Genetic etiology for monozygotic twinning. Birth Defects Orig Artic Ser 1978; 14 (6A): 219-222.

13. Noonan JA. Twins, conjoined twins and cardiac defects. Am J Dis Child 1978; 132: 17-18.

14. Woodward PJ, Sahsey R, Harris DP. et al. Postmortem fetal MR imaging: comparison with findings at autopsy. Am J Roentgenol AJR 1997; 168: 41-46.

15. Manzano AC, Morillo AJ, Vallejo JM, Bayona MP. Necropsy by magnetic resonance in a case of conjoined thoracopagus twins. J Magn Reson Imaging 2001; 13: 976-981.

16. Garden AS, Griffiths RD, Weindling AM, Martin PA. Fast-scan magnetic resonance imaging in fetal visualization. Am J Obstet Gynecol 1991; 164: 1190-1196.

17. Spielmann AL, Freed KS, Spritzer CE. MRI of conjoined twins illustrating advances in fetal imaging. J Comput Assist Tomogr 2001; 25: 88-90. 